\title{
Automatic phonological coding of unattended printed words
}

\author{
GEOFFREY UNDERWOOD and SANDRA THWAITES \\ University of Nottingham, Nottingham NG7 2RD, England
}

\begin{abstract}
A lexical decision response to an attended printed word can be slowed when the word is accompanied by an unattended word that is semantically related. Does this hold for an unattended word that is not related to the target word but sounds as if it is? The homophone WASTE can be shown to affect the lexical decision response to RUBBISH, but how does the incongruently related homophone WAIST affect RUBBISH? If incongruent homophones of words related to the attended word can influence processing when they are not being attended to, then it must be through automatic processing into a phonological code, either before or after lexical access. Experiment 1 reports such an effect, and it is concluded that a phonological representation is generated preattentively and influences the semantic processing of the attended word after generation of that representation. Experiment 2 confirms the effect and investigates the possibility that the effect exists because of the strategic use of phonological encoding of attended words. To discourage the use of a phonological strategy for lexical access, all nonwords were pseudohomophones. The influence persisted, however, with attended words still being affected by the presence of incongruent homophones of related words.
\end{abstract}

Is the appreciation of the meaning of a printed word inevitably associated with the generation of a phonological representation of the word? In these two experiments, this question is asked by observing the influence of unattended words upon responses to simultaneously presented attended words. Printed words can be recognized in circumstances in which the reader is attending to another stimulus and is unable to report the unattended word. This conclusion has been established by observing the influence of the meaning of the unattended word in a variety of tasks performed in response to an attended stimulus, ranging from lexical decision (Underwood, Parry, \& Bull, 1978), to word naming (Allport, 1977; Bradshaw, 1974), picture naming (Underwood, 1976, 1977), retrieval of a paired associate (Underwood, 1980), and category decision (Underwood, 1981). The meanings and graphemic compositions of words that are unavailable to awareness may also influence responses to subsequently presented words (Fowler, Wolford, Slade, \& Tassinary, 1981; Marcel, Note 1). Fowler et al. used a method of preceding a target word, to which a lexical decision had to be made, with a masked priming word. The priming word was presented under conditions that could not leave a conscious trace, and it affected the target word in a number of ways.

Sandra Thwaites is now at the Department of Psychology, University of Waterloo, Ontario N2L 3G1, Canada. This work was supported by Medical Research Council Project Grant G978/1173/N and was improved by discussions with P. O. Holt, G. D. Jennings, and J. M. Rusted. Reprint requests should be sent to Geoffrey Underwood, Department of Psychology, University of Nottingham, Nottingham NG7 2RD, England.
A semantic relationship between prime and target facilitated the lexical decision to the target, and graphemic similarity produced a slower response. Automatic phonological coding has not been investigated in these studies, and so, the present experiments investigate the generation of phonological representations of unattended words. Attention is not necessary for access to the meanings of words, but it is unclear whether access to the meaning is always accompanied by the generation of a phonological code.

Coltheart, Davelaar, Jonasson, and Besner (1977) suggest that the phonological representation is not necessarily produced in a form that is immediately usable by the articulation system and, rather interestingly, that the phonological representation is not necessarily "accessible to introspection" (p. 539). If phonological coding is always performed upon a printed letter string and always results in lexical access, then Coltheart et al. would expect exactly the pattern of results that has emerged from studies of the effects of unattended words: semantic influence without awareness. Indeed, Coltheart et al. go on to suggest that the finding that orthographically legal nonwords produce a larger Stroop effect than illegal nonwords (Bakan \& Alperson, 1967) is a result that should be "interpreted in terms of the automaticity of phonological encoding" (Coltheart et al., 1977, p. 549). The phonological code may be generated either prior to the recognition of the meaning of the word, as Coltheart et al. assume, or after recognition, and these alternatives may be described as the phonological encoding and phonological recoding stages. Lexical access is possible without attention, and so, if phonological encoding is necessary for access 
(Rubenstein, Lewis, \& Rubenstein, 1971), then phonological encoding must also be automatic. Alternatively, the phonological code may be generated only after access has been achieved, and it may not always become available when the meaning is recognized.

The view expressed by Coltheart et al. (1977) is that the generation of the phonological code is automatic, does not necessarily lead to the generation of a conscious trace, and is not necessarily associated with generation of an articulatory code. This leads to a prediction about the effects of unattended words in circumstances in which generation of an unattended code would interfere with processing of the attended word. If we can assume that generation of a phonological code would result in an interaction with the immediate generation of a phonological code to a second word, then the Coltheart et al. model would predict that a phonemically similar prime would influence the lexical decision about a word target. So, HEIGHT should affect a response to BITE because the automatic generation of the phonological code of [hart] would interact with [bart]. Indeed, this pattern of influence has been observed in a task in which lexical decision responses were made to two successive letter strings. Hillinger (1980) found that the decision response to the second word could be facilitated if the previous response was to a word with phonological similarity without graphemic similarity. When the word EIGHT was followed with MATE, a faster response was observed than if the first word was dissimilar. The results of Bakan and Alperson (1967) and Hillinger (1980) tend to support the Coltheart et al. suggestion that phonological codes are generated regard. less of the demands of the task. In Hillinger's experiment, the priming word was attended, however, and in Bakan and Alperson's experiment, the priming word may have been encoded more easily than the orthographically illegal ineffective words. If a phonological code can be generated automatically, then it should be possible to demonstrate an effect of phonological similarity when the priming word is unattended. Unfortunately, phonemic similarity was not varied in the Fowler et al. (1981) experiments, in which masked primes influenced lexical decisions to targets when the prime and target were semantically or graphemically similar.

To investigate the possibility of automatic phonological coding of unattended words, the following experiments adapt a method used previously to investigate the influence of the meanings of unattended printed words (Bradshaw, 1974; Underwood, 1976). When subjects fixate a tachistoscopically presented word, their responses to that word are affected by a semantically related word presented to the parafovea of vision. The question asked here is whether the fixated word can be affected by a heterographic homophone of a related word. A response to the word RUBBISH may be influenced by the presence of WASTE printed a few degrees to one side, but would it be affected by the presence of WAIST? According to Coltheart et al. (1977), each word should be encoded into a phonological representation, and so, we should predict that WASTE and WAIST should be converted to their common phonological form [werst] preattentively. Only if phonological coding is automatic can WAIST affect the processing of RUBBISH. Fowler et al. (1981) and Underwood et al. (1978) found that a lexical decision response can be influenced by the meaning of a related but unattended word, and this task was again used here. A particular advantage of the lexical decision task for the present study is that it requires processing of words without requiring that the stimuli be output using a phonological code. In Experiment 1 , the effect of unattended homophones of words related to simultaneously presented attended words was investigated, and in Experiment 2, the same effect was investigated with all nonwords in the experiment being pseudohomophones, in an attempt to discourage subjects from strategically using phonological coding. To determine whether the phonological code can be activated automatically, these experiments compared the effects upon attended words of related words that were homophones and words that were pseudorelated homophones. Whereas the attended word RUBBISH is a real associate of the homophone WASTE, the other form of this word, WAIST, can be described as being pseudorelated, or as being an incongruently related associate. This semantic relationship is apparent only when the homophones are expressed phonologically.

\section{EXPERIMENT 1}

To determine the influence of an unattended homophone of a related word (i.e., a congruent homophone, as in the RUBBISH-WASTE pairing) upon the lexical decision response to a fixated word, those responses were compared with trials in which homophones were not related to the fixated word (i.e., an incongruous homophone, as in the RUBBISH-WAIST pairing). For comparison, the effect of nonhomophonic related words was examined in comparison with nonhomophonic unrelated words. If the pseudorelated incongruous homophones are influential, then automatic encoding into a phonological form will have been established.

\section{Method}

Subjects. Nine female and seven male subjects were each paid 50 pence for participation in this experiment. All claimed to be right-handed, and all had normal or corrected-to-normal vision.

Stimuli and Design. Each stimulus presentation consisted of a pair of items, with one item designated as the central or attended letter string and the other as the peripheral or unattended letter string. Each letter string could be a word or a nonword, leading to four possible pair types. Word frequencies were matched for central items of the word-word (W-W) and wordnonword (W-NW) pair types, and for the peripheral items of the W-W and nonword-word (NW-W) pair types (Kurera \& Francis, 
1967). Letter strings varied between 3 and 7 letters in length, with a mean of 4.5 letters for both central and peripheral items. The nonwords were orthographically legal, and therefore, pronounceable (e.g., CARTH, SHEEL, THROD).

Four lists (for different groups of subjects) were used, and each contained 120 pairs of items. Each list contained equal numbers of W-W, W-NW, NW-W, and NW-NW pair types. Since the W-NW, NW-W, and NW-NW pairs were not of primary interest, the same examples of these stimuli were employed for all four lists.

The W-W pairs were subdivided equally into three critical conditions and two control conditions. Peripheral items for the critical conditions were selected from 12 pairs of heterographic homophones and from a set of 12 pairs of nonhomophones that were semantically related to the central item. Words were paired such that the peripheral items in one condition were incongruous homophones pseudorelated to the central items (e.g., central item: RUBBISH; peripheral item: WAIST). In the second condition, they were related homophones (e.g., RUBBISHWASTE), and in the third, critical, condition, they were nonhomophones that were related to the central items (e.g., RUBBISHTRASH). Four lists, each containing six examples of these critical conditions, were constructed, with no word appearing more than once and with only one member of each homophonic pair appearing in any one list. An additional constraint was that for the two conditions that employed homophones as peripheral items, half the pairs in each list contained the higher frequency member of the homophonic word pair and half contained the lower frequency member. For the critical word pairs, one list (for one group of subjects) contained the pseudorelated incongruous homophone pair (RUBBISH-WAIST), another (for a second group of subjects) contained the related homophone pair (RUBBISH-WASTE), and another (for another group of subjects) contained a related nonhomophonic pair (RUBBISHTRASH). By this manipulation, subjects responded to the same set of central words for the three experimental conditions, but for different groups of subjects the central word was paired with different peripheral words.

The same W-W control pairs were employed in each of the four lists, in order to provide a constant baseline against which to evaluate any effects of the critical pairs. Central and peripheral items were semantically unrelated. Six pairs contained a heterographic homophone as the peripheral item (e.g., GREENBEAR) and served as a control for both critical conditions that employed homophonic peripheral items. For half of these controls, the peripheral item was the more frequent spelling of the homophone, and for remaining pairs, it was the less frequent spelling (KuCera \& Francis, 1967). The six control pairs for the remaining critical condition used nonhomophonic peripheral items that were unrelated to the central item (e.g., SMILE-THING). The sets of W-W pairs used in this experiment are presented in Appendix $A$.

Practice items consisted of five examples of each of the four possible combinations of words and nonwords. All words were nonhomophones, and words in W-W pairs were unrelated. The 20 practice items were otherwise similar to the experimental items.

Stimuli were printed in black uppercase letters, using Letraset No. 444 on white paper, and were photographed to produce positive slides. A central and peripheral item appeared together on a single slide, with the peripheral item in the right visual field. The center of each attended word appeared in the same position on the screen in every trial, as did the center of each unattended word. The last letter of the attended word varied in distance from the first letter of the unattended word, because words of unequal length were used. The centers of the two words were separated by a distance that corresponded to $4 \mathrm{deg}$ of visual angle from the viewing position of the subject. The spatial arrangement of the two letter strings is indicated in Figure 1.

\section{PRINT PENCIL}
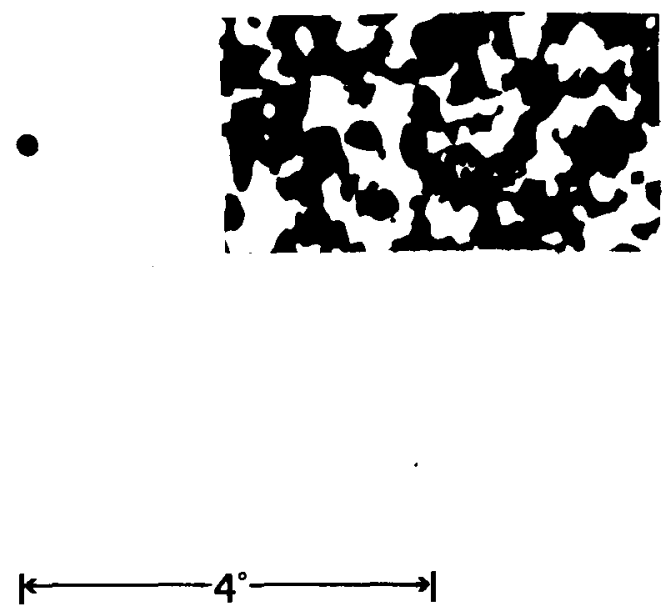

Figure 1. The spatial arrangement of stimuli. The two letter strings were printed and separated as on the top line of the figure. The centers of the two letter strings were separated by a distance that corresponded to $4 \mathrm{deg}$ of visual angle from the viewing position of the subject. The pre- and postexposure fields contained a fixation dot and a masking stimulus, as shown in the second line of the figure. The fixation dot marked a point immediately below the center of the letter string that was to gain the lexical decision response.

Apparatus. Stimuli were back-projected onto a white screen by a Kodak S-AV 2000 projector modified by Forth Instruments, Ltd., for tachistoscopic display. The shutter rise time was $1.5 \mathrm{msec}$. A second, identical, projector was mounted direotly above the first and was used to display a visual noise masking field over the right visual field of the screen, in the area of projection of the peripheral item. The masking stimulus is shown in Figure 1. The two projectors were controlled by a Forth Instruments pulse generator (FI 272). Operation of the pulse generator exposed the test field and turned off the masking field at the same time as starting a Forth Instruments timer (FI 111). The subject sat facing the screen with chin resting on a support. Between the chin rest and the projection screen were two manual response keys. Subjects used the preferred finger of the right hand for operation of the right-hand key and the preferred finger of the left hand for operation of the left-hand key. Depression of either key stopped the timer and illuminated a cue light that indicated which key had been pressed.

Procedure. Each trial consisted of a vocal warning followed shortly by a $50-\mathrm{msec}$ exposure of a central-peripheral pair of letter strings. The pre- and postexposure fields contained a visual noise masking stimulus over the right third of the projection screen. The subjects were required to depress one of the two manual response keys according to whether the central letter string was a word or a nonword. Half the subjects responded to words with the right-hand key and half responded with the left-hand key. Head movements were restrained by the chin rest.

Each subject responded to 20 practice trials and 120 test stimuli. The practice stimuli were the same for all subjects, with 
order of presentation randomly varied. Following the practice session, subjects were presented one of the four lists of test items. Each list was therefore shown to four subjects. Item pairs were presented in a randomized order, arranged in two blocks, but with the constraint that each block contain an equal number of items from each pair type and from each of the W-W conditions. An additional constraint was that no W-W pair occur prior to the seventh trial in each block.

Subjects were instructed to fixate the dot in the center of the screen and to ignore anything that they might see in the periphery of the screen. They were instructed to make the lexical decision response to the central word as quickly and as accurately as possible. All subjects were tested individually and were asked after the experiment what they could report about the peripheral items.

\section{Results and Discussion}

Pair-type analysis. The mean response times and error rates for the four pair types are presented in Table 1. The mean error rate was $6.0 \%$, and since pairs with the higher error rates also exhibited longer response times, a speed-accuracy tradeoff was not in evidence.

A mixed-model analysis of variance was first performed to examine response time as a function of word list (four levels), type of central item (two levels), and type of peripheral item (two levels). The only significant effect was type of central item $[F(1,12)=75.8$, $\mathrm{p}<.001]$, and an examination of the mean latencies revealed that words $(541 \mathrm{msec})$ gained faster responses than nonwords $(651 \mathrm{msec})$. This is a recurrent finding in lexical decision studies, and Coltheart et al. (1977) suggest that it indicates that a nonword decision occurs after some period of time (a deadline) has elapsed in

Table 1

Mean Response Latencies and Error Rates for the Four Stimulus Pairings Used in Experiment 1

\begin{tabular}{lrrrr}
\hline & \multicolumn{2}{c}{ Word Central Item } & \multicolumn{2}{c}{ Nonword Central Item } \\
\cline { 2 - 3 } \cline { 5 - 5 } & \multicolumn{2}{c}{ Peripheral Item } & & \multicolumn{2}{c}{ Peripheral Item } \\
& Word & Nonword & Word & Nonword \\
\hline Mean & 540.4 & 541.3 & 646.7 & 655.5 \\
SD & 40.6 & 41.7 & 71.8 & 68.2 \\
Error Rate & 2.9 & 2.9 & 7.9 & 10.2 \\
\hline
\end{tabular}

Note-Response latencies are given in milliseconds. Error rates are expressed as percentages of the total number of trials within each condition. which no lexical entry has been located for the letter string.

All subjects were debriefed at the end of the experiment and were specifically asked what they had noticed in the periphery of the visual field. None could say that there had been words or nonwords, and often subjects could not say what shape or color of unattended item had been present.

Word-word conditions analysis. Of primary interest was an examination of the response latencies for the five W-W conditons; their means are presented in Table 2 .

These data were analyzed with a mixed-model analysis of variance on two factors, word lists (four levels) and conditions (five levels), with subjects as the random factor. Once again, word lists did not reach significance $(\mathrm{F}<1)$, and neither did the interaction between lists and conditions $(F<1)$. This suggests that there were no reliable departures from generality across the lists sampled. The factor of conditions was reliable $[F(4,48)$ $=2.78, p<.05]$, and three planned comparisons were performed to test the critical conditions against their appropriate controls. One of these comparisons was not orthogonal. When the peripheral word was a nonhomophone that was related to the central word, the latencies were reliably lengthened $[\mathrm{t}(48)=1.7, \mathrm{p}<.05$, onetailed] in comparison with unrelated nonhomophones. This confirms the effect reported by Underwood et al. (1978). An inhibition effect was also apparent for a peripheral item that was an incongruently related homophone $[\mathrm{t}(48)=2.62, \mathrm{p}<.01$, one-tailed $]$ in comparison with unrelated homophones. The third comparison examined the condition in which the peripheral item was related to the central item and was a homophone (e.g., RUBBISH-WASTE) and, since this was tested against the same control as the previous comparison, was not orthogonal. The result was nonsignificant, however $[t(48)=1.11]$. As a check on the dissimilarity of the effect of related and pseudorelated homophones, a further comparison was performed. Although the pseudorelated homophones (e.g., RUBBISH-WAIST) resulted in slightly longer latencies than did the related homophones (RUBBISH-WASTE), the difference was not reliable $[t(48)=1.56]$.

When the data from the $W-W$ conditions were analyzed with items as the random factor, averaging over subjects,

Table 2

Mean Response Latencies (in Milliseconds) and Error Rates (in Percentages) for the Three Critical Conditions and Two Control Conditions of the Word-Word Pairings Used in Experiment 1

\begin{tabular}{|c|c|c|c|}
\hline & \multicolumn{2}{|c|}{ Latency } & \multirow[b]{2}{*}{ Error Rate } \\
\hline & Mean & SD & \\
\hline Incongruously Related Homophone: RUBBISH-WAIST & 559.2 & 47.9 & 3.1 \\
\hline Congruously Related Homophone: RUBBISH-WASTE & 541.4 & 45.1 & 1.0 \\
\hline Nonhomophonic Related Word: RUBBISH-TRASH & 545.0 & 47.2 & 7.3 \\
\hline Homophonic Unrelated Word: GREEN-BEAR & 529.3 & 57.4 & 2.1 \\
\hline Nonhomophonic Unrelated Word: SMILE-THING & 525.6 & 47.2 & 1.0 \\
\hline
\end{tabular}

Note-The descriptions of conditions refer to the relationship of the unattended word to its simultaneously presented attended word. Examples are provided from each condition. The first member of each pair was the letter string to gain the response, and the second member was unattended and masked. 
the effect of conditions was upheld $[F(4,100)=3.27$, $\mathrm{p}<.02]$, and the planned comparisons also suggested the same differences as when subjects were used as the random factor. The comparison of pseudorelated incongruous homophones against the homophone control $[t(100)=2.88, p<.005$, one-tailed ] and that of nonhomophonic related words against the nonhomophonic control $[t(100)=2.02, p<.025$, one-tailed] both suggested reliable differences, whereas the comparison of homophonic congruously related words $[t(100)=$ 1.33] again did not.

Nonhomophonic peripheral words increase the respone latencies to related attended words. This finding has been demonstrated in several other studies and indicates the automaticity of lexical access. Of greater interest here is the result that an interference effect can be observed when the peripheral item is a heterographic homophone of a related word but is not itself related to the attended word. The homophone as printed is not semantically associated to the attended word, but its phonological form is identical to a word that is related. In this experimental condition, a purely graphemic encoding of the peripheral item (e.g., WAIST) would not influence the lexical representation of the central attended item (e.g., RUBBISH), as the two words are semantically unrelated. A phonological representation of the peripheral homophone might activate a phonologically identical representation (e.g., WASTE), which, in turn, could interfere with the processing of the central word. While this finding suggests that one product of graphemic encoding is the automatic availability of the corresponding phonological representation, it is difficult to reconcile this explanation of the finding with the lack of an effect of the related homophone. Although WAIST was seen to influence RUBBISH, the effect of WASTE upon RUBBISH failed to reach reliability. This makes it very difficult to argue that the interference effect of the incongruously related homo. phone was due to activation of the related homophone. However, the comparison did approach significance, and Experiment 2 again employs the five W-W conditions, partly in an attempt to determine whether a related homophone can produce a reliable interference effect and partly to determine whether the effect of unattended homophones can be influenced by the word processing strategy employed by subjects during the course of the experiment.

\section{EXPERIMENT 2}

One problem in concluding that phonological coding is automatic, and responsible for the effects in Experiment 1, derives from the results of Davelaar, Coltheart, Besner, and Jonasson (1978). In their lexical decision study, evidence was found to suggest that phonological coding was more apparent when the nonwords were not pseudohomophones, leading to the conclusion that use of phonological coding is strategy dependent. While it is difficult to argue that, in the present experiments, attention was directed to the peripheral word, it is possible that phonological coding of an attended word may have activated the phonological route and resulted in phonological coding of the unattended word. Once operative, a phonology strategy may proceed automatically upon all available words. To examine this possibility, all the nonwords in Experiment 2 were pseudohomophones, a measure that should bias subjects against using phonological evidence in making each lexical decision. If subjects rely upon the phonological representation before making each lexical decision, then the task cannot be performed when pseudohomophones are present. If the pseudorelated homophone effect from Experiment 1 is upheld in these conditions, then generation of the phonological code may be said to be performed in the absence of the use of a grapheme-phoneme conversion (GPC) strategy for making lexical decisions.

\section{Method}

Subjects. Four female and 10 male subjects were each paid 50 pence for their participation in this experiment. None had taken part in Experiment 1. All subjects were right-handed and had normal or corrected-to-normal vision.

Stimuli, Design, and Procedure. All nonwords were pseudohomophones of words other than those used in the experiment, and, again, lists consisted of W-W, W-NW, NW-W, and NW-NW pairs of letter strings. Some pseudohomophones were selected from the list provided by Coltheart et al. (1977), and others were created specifically for this experiment. One list of 120 pairs was employed, containing equal numbers of items from each pair type. Word frequencies were comparable for central items of the W-W and W-NW pairs and for peripheral items of the W-W and NW-W pairs. Letter-string length was also maintained within the constraints used in Experiment 1.

Word-word conditions. All subjects were presented the same list of W-W items in this experiment. Items for the two critical conditions that employed homophones were randomly selected from one of the lists used in Experiment 1. This ensured that equal numbers of homophones in each condition were the more frequent and less frequent spellings and ensured the presence of only one member of each of the 12 homophone pairs. Six new pairs were selected for the critical condition in which the peripheral item was a nonhomophonic word. The W-W pairs used in this experiment are presented in Appendix B.

The apparatus and procedure were otherwise identical to those in Experiment 1.

\section{Results and Discussion}

Pair-type analysis. The response latencies and error rates for the pair types are presented in Table 3 . The mean error rate was $5.8 \%$, and a speed-accuracy tradeoff was not in evidence, since both higher error rates and longer response latencies occurred when the central item was a nonword.

The latencies were compared with a two-factor withinsubjects analysis of variance to examine the effects of type of central item (two levels) and type of peripheral item (two levels). Central words gained faster lexical decision responses than central nonwords $[F(1,13)=$ $38.11, \mathrm{p}<.001]$. This replicates an effect reported in Experiment 1 and elsewhere, and no other results reached significance. On debriefing, subjects were again unable to report whether words or nonwords had been present in the periphery of vision. 
Table 3

Mean Response Latencies (in Milliseconds) and Error Rates (in Percentages) for the Four Stimulus Pairings Used in Experiment 2, in Which All Nonwords Were Pseudohomophones

\begin{tabular}{lrrrrr}
\hline & \multicolumn{2}{c}{ Word Central Item } & \multicolumn{2}{c}{ Nonword Central Item } \\
\cline { 2 - 3 } \cline { 5 - 6 } & \multicolumn{2}{c}{ Peripheral Item } & & \multicolumn{2}{c}{ Peripheral Item } \\
& Word & Nonword & & Word & Nonword \\
\hline Mean & 568.2 & 559.0 & 661.1 & 688.3 \\
SD & 62.6 & 67.4 & 91.3 & 81.7 \\
Error Rate & 4.5 & 1.2 & 9.8 & 7.6 \\
\hline
\end{tabular}

Table 4

Mean Response Latencies (in Milliseconds) and Error Rates (in Percentages) for the Five Word-Word Conditions Used in Experiment 2

\begin{tabular}{lcccc}
\hline & Mean & SD & $\begin{array}{r}\text { Error } \\
\text { Rate }\end{array}$ \\
\hline Incongruously Related Homophone & 595.6 & 78.9 & 6.0 \\
Congruously Related Homophone & 576.1 & 68.4 & 8.3 \\
Nonhomophonic Related Word & 576.5 & 76.3 & 4.8 \\
Homophonic Unrelated Word & 550.6 & 59.8 & 3.6 \\
Nonhomophonic Unrelated Word & 542.3 & 64.4 & .0 \\
\hline
\end{tabular}

Word-word conditions analysis. The mean response times for the five W-W conditions are presented, with the appropriate error rates, in Table 4 . The W-W conditions were analyzed with a one-factor within-subjects analysis of variance, which indicated the effectiveness of conditions $[F(4,52)=5.36, p<.001]$. The three planned comparisons indicated a reliable inhibition effect for all three critical conditions. When the peripheral word was a related nonhomophone, the response to the central word was slower than when the nonhomophone was unrelated $[\mathrm{t}(52)=2.6, \mathrm{p}<.01$, one-tailed], and when the peripheral word was an incongruously related homophone, the response was slower than when it was an unrelated homophone $[\mathrm{t}(52)=3.4, \mathrm{p}<.005$, one tailed]. A peripheral homophone was also more effective if it was related to the central word $[t(52)=1.9$, $p<.05$, one-tailed], and the failure to confirm this effect in Experiment 1 may have been the result of a Type II error. Comparison of the related and pseudorelated homophones indicated that the difference was not reliable $[t(52)=1.47]$, confirming the report from Experiment 1.

Analysis of the W-W conditions using items as the random factor confirmed the overall effect of conditions $[F(4,25)=3.32, p<.03]$, and the planned comparisons suggested differences similar to those found with subjects treated as the random factor. Incongruously related homophones were compared against homophonic unrelated words $[\mathrm{t}(25)=2.68, \mathrm{p}<.01$, one-tailed $]$. Homophonic related words were also compared against homophonic unrelated words $[\mathrm{t}(25)=1.74, \mathrm{p}<.05$, one-tailed], and nonhomophonic related words were compared against nonhomophonic unrelated words $[\mathrm{t}(25)=1.86, \mathrm{p}<.05$, one-tailed $]$. The comparison of congruously related and incongruously related homophones again indicated no reliable difference $[t(25)=$ $1.2]$.

The presence of the influence of an incongruously related homophone, in an experiment in which generalized use of a GPC strategy was discouraged by the presence of nonword pseudohomophones, suggests that the effect is not dependent upon the strategic phonological processing of the central attended word. Although the lexical decision to the central word could not be made reliably using a phonological code, implying that lexical access should be based upon a route involving direct graphemic analysis, the peripheral word still gained phonological coding. Two interpretations are possible. Either strategic processing of the unattended word is not affected by the strategy used in the processing of the attended word, in which case the deterrent effect of the pseudohomophones will not influence the coding of the unattended word, or the experiment has demonstrated that generation of the phonological code is automatic and that it is generated after the word has gained lexical access. These alternatives will be considered further in the following discussion.

\section{GENERAL DISCUSSION}

The results from these experiments may be summarized as follows. First, when a lexical decision is made to an attended word, the response may be inhibited by the presence of an unattended and semantically related word presented in the same brief display. This effect also exists for an unattended word that is unrelated to the fixated word but is a heterographic homophone of a related word. Thus, the lexical decision response to RUBBISH may be affected by the presence of the word WASTE, but it will also be affected by the presence of WAIST. The pseudorelated homophone can only be effective if its phonological representation has been generated and if the semantic interference effect occurs after generation of the phonological code.

Second, the appearance of the pseudorelated homophone effect in Experiment 2, in which a strategy for lexical decisions based upon phonological encoding would lead to a large number of errors, suggests that the generation of the phonological code occurs after lexical access has been achieved. That is, the experiment may have demonstrated phonological recoding rather than phonological encoding. In Experiment 2, all attended and unattended nonwords were pseudohomophones (e.g., COFF, KREEM, TUTCH), and this measure should discourage the use of a phonological code in making lexical decisions, at least for the attended words. We cannot rule out the possibility, however, that even when the attended word was recognized with a nonphonological strategy the unattended words were encoded with prelexical phonology. Use of pseudohomophones does not necessarily prevent phonological encoding, of course, and can only act to discourage its use in the analysis of nonwords. Davelaar et al. (1978) provide 
evidence that they do act as a deterrent, but uncertainty still exists over the deterrent effect of attended pseudohomophones upon the strategy of processing of unattended words.

Coltheart et al. (1977) suggested that the phonological code is generated automatically and is not necessarily available to awareness. They offered interpretations of two Stroop experiments in support of their suggestions, although the effects in both experiments could have resulted from the operation of a nonphonological route. Bakan and Alperson (1967) demonstrated that legal nonwords result in a larger Stroop interference effect than orthographically illegal nonwords, and Dalrymple-Alford (1972) found an increased Stroop effect for noncolor words that contained phonemes (and graphemes) also to be found in an incongruent color word (e.g., the word BED printed in green ink). These results led Coltheart et al. to suggest that the phonological coding device operates automatically on all printed stimuli, regardless of task demands. In both of these experiments, phonological or graphemic cues could have produced the effect, however, and were not independently varied. Hillinger's (1980) experiment provides better support for the Coltheart et al. position, because phonological priming was produced in the absence of graphemic similarity. In all of these experiments, the effective stimulus was available for inspection and could not be described as fully unattended. Evidence of automatic phonological coding from the effect of incongruously related homophones in the present study confirms the suggestion made by Coltheart et al. for the case of words that are unattended and, according to the introspective reports of subjects, unavailable to awareness. Whereas Coltheart et al. consider that their effects result from automatic phonological encoding, it is possible to interpret the present homophone effect as deriving from automatic phonological recoding.

Why should an unattended word influence the lexical decision response to an unattended word? We may infer that the unattended word WAIST had been analyzed for meaning and converted into a phonological code because it had an interfering influence upon the response to the word RUBBISH. The questions to be asked here concern the locus of interference and the direction of influence.

For a lexical decision response to be made, a letter string must be encoded visually and access its representation in the lexicon. A decision must then be made on the basis of the accumulated visual information according to whether the letter string exists as an independent entry in the lexicon. Presumably, a spelling check could form part of this decision process. Finally, the decision must be organized into a binary response. An influence of an unattended word could, of course, occur at any of these stages, and not necessarily at one alone. However, an influence dependent upon a semantic relationship might be expected to be located after visual encoding of the graphemic pattern of letters and before organization of the manual response. An unattended word may influence lexical access or the decision process, but because recognition of the masked unattended word might be expected to be delayed with respect to recognition of the unmasked attended word (if only because the attended word is fixated upon and is anticipated), it seems more likely that the influence operates after recognition of the attended word. The sequence of processes would then be as follows. Lexical access of the attended word should be accompanied by an automatic spread of activation to its associates in the lexicon, according to the evidence reviewed by Collins and Loftus (1975), Meyer and Schvaneveldt (1971), and Posner and Snyder (1975). All associates of the attended word would thereby be partially activated, and presentation of any one of them would gain facilitated recognition. Once an unattended word has gained access, it may influence any subsequent access to an attended word. It would produce automatic spreading activation itself, for instance, which would in turn influence the attended word, and this diffuse activation in the lexicon might serve to reduce the discriminability of any one word. The decision process would then be delayed while the appropriate letter string was isolated. For the case of pseudorelated words, such as the heterographic homophones of related words used in these experiments, the process is complicated by the emergence of a phonological code.

Presumably, the spread of activation from an attended word does not reach to homophones of related words. The influence of WAIST upon RUBBISH must then follow from the independent recognition of WAIST and its subsequent effect upon the decision process. The phonological code of WAIST may be generated before or after the lexical recognition of the word, but once it is generated, it is available to act in the same manner as the phonological code of WASTE. The phonological code of a pseudorelated homophone, which resembles that of a related word, influences the postlexical processing of the attended word in the same way as does the related word itself. The interference effect suggests that either phonological coding of WAIST into [werst] results in the activation of WASTE. Once the associate has been activated, interference would result from the semantic relationship with the attended word. This referred access model might also expect that the interference would be reduced for heterographic homophones in comparison with the homophonic related words that they resemble, because of the extra stages involved. This was not the case in these experiments, and WAIST was as influential as WASTE upon the processing of RUBBISH. Indeed, the pseudorelated homophones tended to produce more interference than the related homophones, although in neither experiment was this difference statistically reliable. As the interference effect from pseudorelated words tended to be greater rather than smaller than that from related words, however, the referred access model gains no support.

An alternative to the referred access model is the 
phonological recoding model, in which the phonological code is used as the basis for the lexical decision. After words have accessed the lexicon by the graphemic route, the task may depend upon the postlexical generation of the phonological code. If all words are automatically converted into a phonological form at a stage early enough for the code to reaccess the semantic lexicon, then incongruously related homophones may be effective upon the decision processing of attended words.

It is not clear why unattended words should interfere with attended words when the two are related in meaning. This direction of influence has been observed in a number of studies of the latency of response to a target, with both supraliminal and subliminal displays (e.g., Philpott \& Wilding, 1979; Rosinski, Golinkoff, \& Kalish, 1975; Smith \& Magee, 1980; Underwood, 1976, 1977). The traditional Stroop effect of a color word or colorrelated word upon a color-naming task is also an effect of interference (see Dyer, 1973). This direction of influence is perplexing, however, because in many studies a supraliminal nontarget has facilitated the response to a semantically related target (e.g., Fischler, 1977; Neely, 1977; Sperber, McCauley, Ragain, \& Weil, 1979) and the facilitation can also be observed for subliminal nontargets (e.g., Fowler et al., 1981; McCauley. Parmalee, Sperber, \& Carr, 1980; Marcel, Note 1). Why should certain presentations result in interference and others offer facilitation? There is no clear answer to this question, but one speculation concerns the timing of presentation of the influential nontarget stimulus. When the target is presented at the same time as the unattended word, encoding cannot be affected, because the target will be processed at an advantage over the nontarget. If the nontarget is recognized more slowly than the attended target, then its influence upon encoding must be minimal. Influence must then reside in the decision process or in the output processes. When related memory locations are simultaneously activated, the decision process may be impaired, because a further stage may be necessary to isolate the stimulus that should receive further processing.

\section{REFERENCE NOTE}

1. Marcel, A. J. Conscious and unconscious perception: Visual masking, word recognition, and an approach to consciousness. Unpublished manuscript, MRC Applied Psychology Unit, Cambridge, England, 1980.

\section{REFERENCES}

Allport, D. A. On knowing the meanings of words we are unable to report: The effects of masking. In S. Dornic (Ed.), Attention and performance VI. Hillsdale, N.J: Erlbaum, 1977.

Bakan, P., \& Alperson, B. Pronouncability, attensity, and interference in the color-word test. American Journal of Psychology, 1967, 80, 416-420.

Bradshaw, J. L. Peripherally presented and unreported words may bias the perceived meaning of a centrally fixated homograph. Journal of Experimental Psychology, 1974, 103, 1200 1202.
Collins, A. M., \& Loftus, E. F. A spreading activation theory of semantic processing. Psychological Review, 1975, 82, 407-428.

Coltheart, M., Davelaar, E., Jonasson, J, T., \& Besner, D. Access to the internal lexicon. In S. Dornic (Ed.), Attention and performance VI. Hillsdale, N.J: Erlbaum, 1977.

Dalrymple-Alford, E. C. Sound similarity and color word interference in the Stroop effect. Psychonomic Science, 1972, 28, 209-210.

Davelaar, E., Coltheart, M., Besner, D., \& Jonasson, J. T. Phonological recoding and lexical access. Memory \& Cognition, 1978, 6, 391-402.

Dye R, F. N. The Stroop phenomenon and its use in the study of perceptual, cognitive and response processes. Memory \& Cognition, 1973, 1, 106-120.

Fischler, I. Associative facilitation with expectancy in a lexical decision task. Journal of Experimental Psychology: Human Perception and Performance, 1977, 3, 18-26.

Fowler, C. W., Wolford, G., Slade, R., \& Tassinary, L. Lexical access with and without awareness. Journal of Experimental Psychology: General, 1981, 110, 341-362.

Hillinger, M. L. Priming effects with phonemically similar words: The encoding bias hypothesis reconsidered. Memory \& Cognition, 1980, 8, 115-123.

Kučera, H., \& Francis, W. N. Computational analysis of present-day American English. Providence, R.I: Brown University Press, 1967.

McCauley, C., Parmalee, C. M., Sperber, R. D., \& Carr, T. H. Early extraction of meaning from pictures and its relation to conscious identification. Journal of Experimental Psychology: Human Perception and Performance, 1980, 6, 265276.

Meyer, D., \& Schvaneveldt, R. W. Facilitation in recognizing pairs of words: Evidence of a dependence between retrieval operations. Journal of Experimental Psychology, 1971, 90, 227-234.

NeELy, J. H. Semantic priming and retrieval from lexical memory: Roles of inhibitionless spreading activation and limited capacity attention. Journal of Experimental Psychology: General, 1977, 106, 226-254.

Philpott, A., \& Wilding, J. Semantic interference from subliminal stimuli in a dichoptic viewing situation. British Journal of Psychology, 1979, 70, 559-563.

Posner, M. I., \& Snyder, C. R. R. Attention and cognitive control. In R. Solso (Ed.), Information processing and cognition: The Loyola symposium. Potomac, Md: Erlbaum, 1975.

Rosinski, R. R., Golinkoff, R. M., \& Kukish, K. Automatic semantic processing in a picture-word interference task. Child Development, 1975, 46, 247-253.

Rubenstein, H., Lewis, S. S., \& Rubenstein, M. A. Evidence for phonemic recoding in visual word recognition. Journal of Verbal Learning and Verbal Behavior, 1971, 10, 745-757.

Smith, M. C., \& Magee, L. E. Tracing the time course of picture-word processing. Journal of Experimental Psychology: General, 1980, 109, 373-392.

Sperber, R. D., McCauley, C., Ragain, R. D., \& Weil, C. Semantic priming effects on picture and word processing. Memory \& Cognition, 1979, 7, 339-345.

UNDERWOOD, G. Semantic interference from unattended printed words. British Journal of Psychology, 1976, 67, 327-338.

UNDE RWOOD, G. Attention, awareness and hemispheric differences in word recognition. Neuropsychologia, 1977, 15, 61-67.

UNDERWOOD, G. Attention and the nonselective lexical access of ambiguous words. Canadian Journal of Psychology, 1980, 34, 72-76.

UNDERWOOD, G. Lexical recognition of embedded unattended words: Some implications for reading processes. Acta Psychologica, 1981, 34, 267-283.

Unde rwood, G., Parry, R. S., \& Bull, L. A. Simple reading tasks are affected by unattended context. In $M$. Gruneberg, P. E. Morris, \& R. N. Sykes (Eds.), Practical aspects of memory. London: Academic Press, 1978. 
Appendix A

Stimuli Used in the Word-Word Conditions in Experiment 1

\begin{tabular}{|c|c|c|c|c|}
\hline $\begin{array}{l}\text { Unrelated Unattended } \\
\text { Words }\end{array}$ & List A & List B & List $\mathrm{C}$ & List D \\
\hline Homophonic & \multicolumn{4}{|c|}{ Incongruously Related Homophones as Unattended Words } \\
\hline GREEN-BEAR & MANY-SUM & LEFT-WRITE & THREE-WON & HER-HYMN \\
\hline SAID-ROAD & SKY-BLEW & FEW-NUN & VISION-CITE & BUD-ROWS \\
\hline CHAIN-OUR & RUBBISH-WAIST & PLANT-FLOUR & BITTER-SUITE & STORM-REIGN \\
\hline MILK-WEAK & PRINT-RIGHT & ADD-SOME & CHOIR-HIM & LOST-ONE \\
\hline TANK-PEAR & PRIEST-NONE & PUFF-BLUE & COLUMN-ROSE & QUOTE-SIGHT \\
\hline SMALL-WHINE & CAKE-FLOWER & HIPS-WASTE & KING-RAIN & HOTEL-SWEET \\
\hline Nonhomophonic & \multicolumn{4}{|c|}{ Congruously Related Homophones as Unattended Words } \\
\hline SMILE-THING & THREE-ONE & HER-HIM & MANY-SOME & LEFT-RIGHT \\
\hline DEEP-BRUSH & VISION-SIGHT & BUD-ROSE & SKY-BLUE & FEW-NONE \\
\hline CLEAN-WHEEL & BITTER-SWEET & STORM-RAIN & RUBBISH-WASTE & PLANT-FLOWER \\
\hline COAL-MASK & CHOIR-HYMN & LOST-WON & PRINT-WRITE & ADD-SUM \\
\hline MONEY -SUCH & COLUMN-ROWS & QUOTE-CITE & PRIEST-NUN & PUFF-BLEW \\
\hline \multirow[t]{8}{*}{ LIKE-HIGH } & KING-REIGN & HOTEL-SUITE & CAKE-FLOUR & HIPS-WAIST \\
\hline & \multicolumn{4}{|c|}{ Nonhomophonic Related Words as Unattended Words } \\
\hline & HER-SHE & THREE-FIVE & LEFT-DOWN & MANY-MOST \\
\hline & BUD-LEAF & VISION-EYES & FEW-MOST & SKY-CLOUD \\
\hline & STORM-CLOUD & BITTER-SOUR & PLANT-LEAF & RUBBISH-TRASH \\
\hline & LOST-VICTORY & CHOIR-SONG & ADD-MATHS & PRINT-PENCIL \\
\hline & QUOTE-REFER & COLUMN-PILLAR & PUFF-SMOKE & PRIEST-CHURCH \\
\hline & HOTEL-ROOM & KING-ROYAL & HIPS-LEGS & CAKE-PASTRY \\
\hline
\end{tabular}

Note-Each subject was given the same lists of unrelated homophone controls and unrelated nonhomophone controls. The four lists of incongruous homophones, congruous homophones, and nonhomophones all related to the attended word and were seen by groups of four subjects each. In all of the pairs here, the first word was the central, attended, word and the second word was the peripheral, unattended, word.

Appendix B

Stimuli Used in Experiment 2

\begin{tabular}{lcccc}
\hline $\begin{array}{c}\text { Homophonic Unrelated } \\
\text { Unattended Words }\end{array}$ & $\begin{array}{c}\text { Nonhomophonic Unrelated } \\
\text { Unattended Words }\end{array}$ & $\begin{array}{c}\text { Incongruously Related } \\
\text { Homophones as } \\
\text { Unattended Words }\end{array}$ & $\begin{array}{c}\text { Congruently Related } \\
\text { Homophones as } \\
\text { Unattended Words }\end{array}$ & $\begin{array}{c}\text { Nonhomophonic Related } \\
\text { Words as Unattended } \\
\text { Words }\end{array}$ \\
\hline MILK-WEAK & SMILE-THING & LEFT-WRITE & LOST-WON & POOL-SWIM \\
CHAIN-OUR & SHAPE-COIN & FEW-NUN & HER-HIM & TOWN-CITY \\
HEAD-WHINE & STUDY-BACK & PUFF-BLUE & QUOTE-CITE & CAT-KITTEN \\
TOWER-HAIR & DEEP-BRUSH & PLANT-FLOUR & BUD-ROSE & STAR-MOON \\
TANK-PEAR & LIKE-HIGH & ADD-SOME & HOTEL-SUITE & SALT-PEPPER \\
SAID-ROAD & TIME-WILD & HIPS-WASTE & STORM-RAIN & KICK-HIT \\
\hline
\end{tabular}

Note-Each subject saw each of the pairs in each group of word-word pairs. The first word in each pair was the central, attended, word. 